\title{
Introgression of Traits from Wild Diploids into Cultivated Tetraploids: A Pragmatic Analysis Using Genetic and Cytogenetic Tool
}

\author{
L. Mahalingam $^{1 *}$, N. Premalatha ${ }^{1}$, K. Senguttuvan ${ }^{1}$, B. Rakavi $^{2}$ and M. Kumar ${ }^{3}$ \\ ${ }^{1}$ Department of Cotton, Centre for Plant Breeding and Genetics, Tamil Nadu \\ Agricultural University, Coimbatore- 641 003, Tamil Nadu, India \\ ${ }^{2}$ Department of Crop Physiology, Tamil Nadu Agricultural University, Coimbatore- \\ 641 003, Tamil Nadu, India \\ ${ }^{3}$ Tamil Nadu Agricultural University, Coimbatore-641003, Tamil Nadu, India \\ *Corresponding author
}

\section{A B S T R A C T}

\section{Keywords}

Wild diploids, Cultivated tetraploids, Cytogenetic tool

Article Info

Accepted:

14 June 2020

Available Online:

10 July 2020
Interspecific triploid hybrid was developed between tetraploid cultivated species Gossypium hirsutum cv. MCU 5 and CO 14 and diploid wild species Gossypium anomalum. The $\mathrm{F}_{1}$ hybridity was confirmed by morphological and cytologicalstud. The ploidy level of interspecific $F_{1}$ hybrid was triploid and male sterile. Maternal parents MCU 5 and CO 14 had erect growth habit, green stem, palmate leaves, thick and prominent leaf veins, cream petals and embedded stigma. MCU5 was with dense yellow anthers while CO 14 dense creamy anthers, whereas male parent Gossypium anomalum has spreading growth habit, dull violet petals, pale brownish green stem, creamy white, thin leaf veins, embedded stigma and strongly hairyness plant body. The growth habit, leaf shape and petal colour and petal size of interspecific $F_{1}$ hybrids were similar to the paternal parent. Plant stem colour, hairiness, leaf pubescence and anther colour of Gossypium anomalum were observed to be dominant as hybrid fully resembled Gossypium anomalum for these characters. Petal spot was observed in Gossypium anomalum and in $\mathrm{F}_{1}$ hybrids while petal spot was not observed in MCU 5 and CO 14. Variable expression of petal spot, anther colour and filament colour was observed in the $\mathrm{F}_{1}$ hybrids. The mitotic study revealed that the maternal parent MCU 5 and CO 14 with 52 chromosomes, Gossypium anomalum had 26 chromosomes and the interspecific $F_{1}$ was with 39 chromosomes. Significant differences were observed between pollen size, pollen fertility of parents and their hybrids. The $F_{1}$ interspecific hybrids having more than 97 percent of sterile pollen grains. This $F_{1}$ may be utilized as a pre breeding genetic resource for transfer of cotton jassid resistance to American cotton in breeding programme.

\section{Introduction}

The genus Gossypium encompasses 50 species (45 diploids and five allopolyploids) which were distributed in tropical and subtropical region of the world (Fryxell, 1992). Out of the four cultivated species Gossypium hirsutum L. $\left(2 \mathrm{n}=4 \mathrm{x}=52, \mathrm{~A}_{1} \mathrm{D}_{1}\right)$ is 
contributing 90 per cent of the cotton production worldwide. The other three cultivated species are the African diploid Gossypium herbaceum $\left(2 \mathrm{n}=2 \mathrm{x}=26, \mathrm{~A}_{2}\right)$, the Asian and Indian Diploid Gossypium arboretum $\left(2 \mathrm{n}=2 \mathrm{x}=26, \mathrm{~A}_{1}\right)$, and the New World tetraploid Gossypium barbadense $\left(2 \mathrm{n}=4 \mathrm{x}=52, \quad \mathrm{~A}_{2} \mathrm{D}_{2}\right)$. Diploid Gossypium species fall into eight cytological groups designated $A-G$ and $K$ based on the chromosomal pairing relationship and the geographical distribution (Wendel, 1989; Percival and Wendel, 1999). Wild species of cotton represent a significant genetic repository for potential exploitation by cotton breeders who have long recognized the beneficial effect of exotic genes (Heitholt and Manney, 2010). The introduction of alien genetic variation into upland cotton from the chromosome of the wild species is a valuable and proven technique for cotton improvement. The most successful examples of the use of wild species during the history of cotton breeding include Gossypium harknessii as a source of cytoplasmic male sterility (Meyer, 1975) and Gossypium thurberi as a source of fibre quality (Culp and Harrell, 1973; Culp et al., 1979). More recently, other important traits such as nematode resistance and low gossypol plant traits were successfully introduced from diploid species into upland cotton using various strategies (Sacks and Robinson, 2009; Benbouza et al., 2010). Despite of these successes the most of the genetic variation in wild Gossypium species remains to be exploited.

Gossypium anomalum is a wild species belonging to the $B_{1}$ genome group. Gossypium anomalum grows in Southwest Africa and along the southern fringes of Sahara almost from the Atlantic to the Redsea (Fryxell, 1920). As a member of Subsection of Anomalo Todaro, Gossypium anomalum possess several desirable characters such as extremely fine fibres, good strength, low fibre weight, resistance to insect pests, immunity to the diseases black arm and bacterial blight and tolerance to water deficit(Ganesh et al., 2013).Some efforts have been made to introduce desirable characters from Gossypium anomalumto the cultivated cotton (Liu et al., 1992; Mehetre, 2010). Gossypium anomalum represents an inestimable source of genes that can potentially be transferred to the cultivated cotton gene pool.

\section{Materials and Methods}

The crossing block has been raised during summer 2019 season in the field number C3 comprising of two maternal parents viz., MCU 5 and CO14. The male parent Gossypium anomalum is maintained at Cotton Wild Species Garden. Crosses were effected by using Doak's method of hand emasculation and pollination and the crossed bolls were collected. The hybrids along with their female parents viz., MCU5 and CO 14 were raised in field C3 field during Winter 2019 and the male parent Gossypium anomalum is being maintained at Cotton Wild Species Garden. The various morphological and cytological observations recorded in parents and $F_{1}$ hybrids (Plate 1 and 2).

Nineteen morphological characters viz., growth habit, stem colour, stem pubescence, petiole colour, leaf shape, leaf colour, leaf incision, leaf veins, leaf texture, leaf hairiness, bract size, corolla colour, petal size, petal spot, anther colour, anther density, filament colour, position of stigma and nectar glands were recorded for hybridity confirmation. A total of 14 biometrical traits namely number of bracterial teeth, bracterial length, bracterial breadth, petiole length, leaf length, leaf breadth, leaf area, pedicel length, petal length, petal breadth, pollen size diameter, pollen fertility (\%), length of pistil and gossypol gland density were observed on both the parents and $\mathrm{F}_{1}$ hybrids. 
Fourth fully matured and expanded leaves from the top of the plant were taken and their maximum length and breadth was recorded. Leaf area was measured from 5 fully expanded matured leaves of both parents and $\mathrm{F}_{1}$ hybrids using leaf area meter and averaged. Flowers were collected in morning on the day of anthesis between 10.00 am to 11.00 am for pollen fertility study. Pollen fertility was recorded by dusting pollen grains in $1 \% \mathrm{KI}$ solution and viewed under a compound microscope. Only large, darkly stained and circular pollen grains were considered as fertile. In both parents and $F_{1}$ hybrids four microscopic fields were taken to find out the pollen fertility percentage and averaged.

The mitotic metaphase chromosome study was carried out by using root tips as explant to find out the ploidy level of $F_{1}$ hybrids and their parents. Seeds of parents and their $\mathrm{F}_{1}$ hybrids soaked for overnight and germinated in the germination paper. The roots were collected from the germinated seeds with $2-3 \mathrm{~cm}$ length in quick succession between 9.00 am to10.00 am on bright sunny days and pretreated in paradichloro benzene to accumulate metaphase cells. After 2 hours the pretreated root tips washed thorouhgly in running tap water and fixed in the ethanol: glacial acetic acid (3:1) fixative. After keeping the fixed material under low temperature $\left(4^{\circ} \mathrm{C}\right)$ for a minimum period of four hours, the roots were thoroughly washed in the distilled water and stored in $70 \%$ ethanol. The roots were hydrolysed at $60^{\circ} \mathrm{C}$ for 5 minutes and washed thoroughly. Then the root tips are treated in a $0.25 \%$ pectinase solution for 15 minutes in dark and putit in basic fuchsin stain for 30 minutes in dark. The darkly stained extreme tip portion of the roots were excised out and macerated in a drop of $1 \%$ acetocarmine. After maceration the slide covered with cover slip and heated gently over a sprit lamp. The excess stain was removed by giving gentlepress with thumb between two layers of filter paper. The slide was temporarily sealed using wax and observed under the Olympus system microscope@1000X magnification. The chromosomes were counted from the metaphase cells and recorded pictorially.

\section{Results and Discussion}

Morphological characters of parents (MCU 5, $\mathrm{CO} 14$ and Gossypium anomalum) and $\mathrm{F}_{1}$ hybrids (MCU 5 x Gossypium anomalum and CO 14 x Gossypium anomalum) were compared and presented in Table 1 and 2. MCU 5 and CO 14 had annual plant growth habit, whereas the $\mathrm{F}_{1}$ hybrids and pollen parent Gossypium anomalum exhibited perennial shrub growth habit. The pollen parent and both the $F_{1}$ interspecific hybrids recorded pale brownish green colour stem whereas MCU 5 and CO 14 exhibited greenish brown stem colour. Sparsely pubescent stem were noticed in both female parents (MCU 5 and CO 14) while, the male parent and two $\mathrm{F}_{1}$ hybrids viz., MCU $5 \mathrm{x}$ Gossypium anomalum and $\mathrm{CO} 14 \mathrm{x}$ Gossypium anomalum showed stem with strong pubescence. The leaf veins in maternal parents (MCU 5 and $\mathrm{CO}$ 14) and in two interspecific $\mathrm{F}_{1}$ hybrids (MCU 5 x Gossypium anomalum and $\mathrm{CO} 14$ x Gossypium anomalum) were thick and prominent in nature whereas the pollen parent Gossypium anomalum showed thin nature of veins. The medium smooth leaf texture was observed in maternal parents (MCU 5 and $\mathrm{CO}$ 14) but in male parent (Gossypium anomalum) and $\mathrm{F}_{1}$ hybrids velvety nature of leaf texture were noticed. Leaf with strong hairiness was observed in $\mathrm{F}_{1}$ hybrids and Gossypium anomalum whereas, the maternal parents showed sparsely hairy nature of leaf. The corolla colour of maternal parents(MCU 5 and $\mathrm{CO} 14$ ) were creamy white but dull violet coloured corolla were observed in $\mathrm{F}_{1}$ hybrids 
(MCU 5 x Gossypium anomalum and CO 14 x Gossypium anomalum).

The maternal parents, $\mathrm{F}_{1}$ hybrids and paternal parent Gossypium anomalum exhibited same expression for petalsize, anther colour, filament colour, position of stigma and nectar gland traits (Plate 3,4 and 7).

Out of 19 qualitative characters observed, three characters viz., growth habit, leaf incision and corolla colour were showed intermediate between both parents in the $\mathrm{F}_{1}$ hybrids.Similar results were reported by Kaur et al., (2016) in the $\mathrm{F}_{1}$ hybrids Gossypium hirsutum $x$ Gossypium armourianum for the characters like growth habit and petal colour. Manickam and Prakash (2014) also reported the intermediate leaf and flower morphology in Gossypium hirsutm $x$ Gossypium armourianum hybrid. Petal colour of Gossypium arboreum $x$ Gossypium hirsutum hybrid and its reciprocal crosses were found be intermediate (Ahmad et al., 2011; Tahir et al., 2011). Kale et al., (2007) reported as the $\mathrm{F}_{1}$ hybrid of Gossypium arboretum $x$ Gossypium thurberihad showed dull violet petal colour and which is similar to the female parent. The $\mathrm{F}_{1}$ hybrid of Gossypium herbaceumx Gossypium raimondii exhibited dominance for the anther colour and it is identical to the maternal parent $(\mathrm{Wu}$ et al., 2017).

The morphological traits namely stem colour, stem pubescence and hairiness observed in MCU 5 x Gossypium anomalum and CO $14 \mathrm{x}$ Gossypium anomalum hybrids found to be dominant and resembled with male parent Gossypium anomalum. Both the hybrids(MCU 5 x Gossypium anomalum and CO 14 x Gossypium anomalum) were showed dominant expression for leaf texture and leaf hairiness and which was more similar to its male parent Gossypium anomalum. Kaur et al., (2016) also reported similar dominant expression for stemcolour, leaf pubescence and leaf hairiness as fully resembled Gossypium armourianum in the Gossypium hirsutum cv., $1861 x$ Gossypium armourianum $\mathrm{F}_{1}$ hybrid. Average leaf length, leaf breadth and leaf area of MCU 5 x Gossypium anomalum and CO 14 x Gossypium anomalum hybrids were observed to be intermediate between both parents. Highly significant differences were observed between male and female parents as well as between the parents and hybrids. This results were in agreement with Kaur et al., (2016) and Wu et al., (2017).

The female parents MCU 5 and CO 14 and the male parent Gossypium anomalum recorded the average pollen fertility of $92.55 \%, 93.33 \%$ and $94.10 \%$ respectively. $F_{1}$ hybrids MCU 5 x Gossypium anomalum and CO 14 x Gossypium anomalumwere highly sterile with the pollenfertility of $2.17 \%$ and $0.7 \%$ respectively (Plate 5). Kaur et al., (2016) noticed $2.19 \%$ of average pollen fertility in the $\mathrm{F}_{1}$ hybrid of Gossypium hirsutum cv., 1861 x Gossypium armourianum. Pushpam and Raveendran (2006) reported that the average pollen fertility of $9.04 \%$ and $9.67 \%$ in Gossypium hirsutum $x$ Gossypium armourianum and Gossypium hirsutum $x$ Gossypium raimondii respectively

Mitotic metaphase counts revealed that the presence of 52 chromosomes in Gossypium hirsutum $c v$. MCU 5 and $\mathrm{CO}$ 14, 26 chromosomes in Gossypium anomalum and, 39 chromosomes in corresponding $\mathrm{F}_{1}$ hybrids and confirmed the hybridity and triploid status of the $F_{1}$ hybrids developed from cross between MCU 5 x Gossypium anomalum and CO 14 x Gossypium anomalum (Plate 6). This results in agreement with Manickam and Prakash (2014). 
Table.1 Morphological traits of parents and $\mathrm{F}_{1}$ hybrid of MCU 5 x Gossypium anomalum

\begin{tabular}{|r|l|l|l|l|}
\hline S. No & Characters & \multicolumn{1}{|c|}{ MCU 5 } & \multicolumn{1}{|c|}{ MCU 5 x G.anomalum } & \multicolumn{1}{|c|}{.anomalum } \\
\hline $\mathbf{1}$ & Growth habit & Annual,erect & Perennial shrub & Perennial shrub \\
\hline $\mathbf{2}$ & Stem colour & Dark green with brown & Pale brownish green & Pale brownish \\
\hline $\mathbf{3}$ & Leaf colour & Green & Green & Dull green \\
\hline $\mathbf{4}$ & Leaf incision & Shallow to slightly deep & Medium to deep & Deep \\
\hline $\mathbf{5}$ & Leaf shape & Palmate with 2-3 lobes & Palmate with 5 lobes & Palmate with 5 lobes \\
\hline $\mathbf{6}$ & Leaf texture & Medium smooth & Velvety & Velvety \\
\hline $\mathbf{7}$ & Leaf veins & Thick and prominent & Thick and prominent & Thin \\
\hline $\mathbf{8}$ & Petiole colour & Greenish brown & Greenish brown & Dull green with brown \\
\hline $\mathbf{9}$ & Leaf hairyness & Sparsely hairy & Strongly hairy & Strongly hairy \\
\hline $\mathbf{1 0}$ & Stem pubescence & Sparsely pubescent & Strongly pubescent & Strongly pubescent \\
\hline $\mathbf{1 1}$ & Corolla colour & Creamy white & Dull white & Dull violet \\
\hline $\mathbf{1 2}$ & Anther colour & Yellow & Yellow & Creamy white \\
\hline $\mathbf{1 3}$ & Anther density & Dense & Dense and compact & Dense and compact \\
\hline $\mathbf{1 4}$ & Bract size & Medium & Medium & Very small \\
\hline $\mathbf{1 5}$ & Petal size & Medium & Medium & Medium \\
\hline $\mathbf{1 6}$ & Petal spot & Absent & Present (dark red spot) & Present (dark red spot) \\
\hline $\mathbf{1 7}$ & Filament colour & White to creamy white & White to creamy white & White to creamy white \\
\hline $\mathbf{1 8}$ & Position of stigma & Embedded & Embedded & Embedded \\
\hline $\mathbf{1 9}$ & Nectar gland & Present & Present & Present \\
\hline
\end{tabular}

Table.2 Morphological traits of parents and $\mathrm{F}_{1}$ hybrid of $\mathrm{CO} 14$ x Gossypium anomalum

\begin{tabular}{|r|l|l|l|l|}
\hline S. No & \multicolumn{1}{|c|}{ Characters } & \multicolumn{1}{|c|}{ CO 14 } & \multicolumn{1}{|c|}{ CO 14 x G.anomalum } & \multicolumn{1}{|c|}{ Perennial shrub } \\
\hline $\mathbf{1}$ & Growth habit & Annual , erect & Perennial shrub & Pale brownish \\
\hline $\mathbf{2}$ & Stem colour & Dark green & Pale brownish green & Dull green \\
\hline $\mathbf{3}$ & Leaf colour & Green & Green & Deep \\
\hline $\mathbf{4}$ & Leaf incision & Shallow to slightly deep & Medium to deep & Palmate with 5 lobes \\
\hline $\mathbf{5}$ & Leaf shape & Palmate with 2-4 lobes & Palmate with 5 lobes & Velvety \\
\hline $\mathbf{6}$ & Leaf texture & Medium smooth & Velvety & Thin \\
\hline $\mathbf{7}$ & Leaf veins & Thick and prominent & Thick and prominent & Dull green with brown \\
\hline $\mathbf{8}$ & Petiole colour & Light green & Greenish brown & Strongly hairy \\
\hline $\mathbf{9}$ & Leaf hairyness & Sparsely hairy & Strongly hairy & Strongly pubescent \\
\hline $\mathbf{1 0}$ & Stem pubescence & Sparsely pubescent & Strongly pubescent & Dull violet \\
\hline $\mathbf{1 1}$ & Corolla colour & Creamy white & Dull white & Creamy white \\
\hline $\mathbf{1 2}$ & Anther colour & Creamy white & Creamy white & Dense and compact \\
\hline $\mathbf{1 3}$ & Anther density & Dense & Dense and compact & Very small \\
\hline $\mathbf{1 4}$ & Bract size & Medium & Medium & Medium \\
\hline $\mathbf{1 5}$ & Petal size & Medium & Medium & Present (dark red spot) \\
\hline $\mathbf{1 6}$ & Petal spot & Absent & Present (dark red spot) & White to creamy white \\
\hline $\mathbf{1 7}$ & Filament colour & White to creamy white & White to creamy white & Embedded \\
\hline $\mathbf{1 8}$ & Position of stigma & Embedded & Embedded & Present \\
\hline $\mathbf{1 9}$ & Nectar gland & Present & Present & \\
\hline & & & & \\
\hline
\end{tabular}


Table.3 Biometrical traits of MCU 5 x Gosspium anomalum hybrid and their parents

\begin{tabular}{|c|l|c|c|c|}
\hline S.No & Characters & MCU 5 & MCU 5 x G.anomalum & G.anomalum \\
\hline $\mathbf{1}$ & Number of bracterial teeth & $9.66^{* *}$ & $6.20^{* *}$ & $2.60^{* *}$ \\
\hline $\mathbf{2}$ & Bracterial length $(\mathrm{cm})$ & $3.78^{* *}$ & $3.52^{* *}$ & $1.62^{* *}$ \\
\hline $\mathbf{3}$ & Bracterial breadth $(\mathrm{cm})$ & $2.77^{* *}$ & $2.20^{* *}$ & $0.46^{* *}$ \\
\hline $\mathbf{4}$ & Petiole length $(\mathrm{cm})$ & $11.75^{* *}$ & $7.52^{* *}$ & $4.28^{* *}$ \\
\hline $\mathbf{5}$ & Leaf length $(\mathrm{cm})$ & $13.91^{* *}$ & $10.22^{* *}$ & $5.68^{* *}$ \\
\hline $\mathbf{6}$ & Leaf breadth $(\mathrm{cm})$ & $13.25^{* *}$ & $10.34^{* *}$ & $5.00^{* *}$ \\
\hline $\mathbf{7}$ & Leaf area $\left(\mathrm{cm}^{2}\right)$ & $154.85^{* *}$ & $62.99^{* *}$ & $15.16^{* *}$ \\
\hline $\mathbf{8}$ & pedicel length $(\mathrm{cm})$ & $1.27^{\mathrm{b}}$ & $1.22^{\mathrm{b}}$ & $0.48^{\mathrm{a}}$ \\
\hline $\mathbf{9}$ & Petal length $(\mathrm{cm})$ & $3.87^{* *}$ & $4.12^{* *}$ & $3.28^{* *}$ \\
\hline $\mathbf{1 0}$ & Petal breadth $(\mathrm{cm})$ & $3.50^{* *}$ & $4.02^{* *}$ & $3.44^{* *}$ \\
\hline $\mathbf{1 1}$ & Pollen size diameter( $\mu)$ & $39.51^{* *}$ & $25.12^{* *}$ & $35.56^{* *}$ \\
\hline $\mathbf{1 2}$ & Pollen fertility $(\%)$ & $92.55^{* *}$ & $2.17^{* *}$ & $94.10^{* *}$ \\
\hline $\mathbf{1 3}$ & Length of pistil $(\mathrm{cm})$ & $2.27^{\mathrm{b}}$ & $2.24^{\mathrm{b}}$ & $1.74^{\mathrm{a}}$ \\
\hline $\mathbf{1 4}$ & Gossypol gland density & $11.00^{\mathrm{b}}$ & $8.50^{\mathrm{a}}$ & $9.75^{\mathrm{a}}$ \\
\hline
\end{tabular}

** Significant difference at $\mathrm{P}<0.01$ using Duncan's Multiple Range Test

The letters in the same alphabet are considered as non -significant

Table.4 Biometrical traits of CO 14 x G. anomalum hybrid and their parents

\begin{tabular}{|c|l|c|c|c|}
\hline S.No. & Characters & CO 14 & CO 14 x G. anomalum & G.anomalum \\
\hline $\mathbf{1}$ & Number of bracterial teeth & $10.00^{* *}$ & $5.40^{* *}$ & $2.60^{* *}$ \\
\hline $\mathbf{2}$ & Bracterial length $(\mathrm{cm})$ & $4.27^{* *}$ & $3.44^{* *}$ & $1.62^{* *}$ \\
\hline $\mathbf{3}$ & Bracterial breadth $(\mathrm{cm})$ & $1.95^{* *}$ & $2.14^{* *}$ & $0.46^{* *}$ \\
\hline $\mathbf{4}$ & Petiole length $(\mathrm{cm})$ & $12.21^{* *}$ & $8.02^{* *}$ & $4.28^{* *}$ \\
\hline $\mathbf{5}$ & Leaf length $(\mathrm{cm})$ & $14.97^{* *}$ & $11.16^{* *}$ & $5.68^{* *}$ \\
\hline $\mathbf{6}$ & Leaf breadth $(\mathrm{cm})$ & $14.80^{* *}$ & $10.74^{* *}$ & $5.00^{* *}$ \\
\hline $\mathbf{7}$ & Leaf area $\left(\mathrm{cm}^{2}\right)$ & $157.73^{* *}$ & $60.51^{* *}$ & $15.16^{* *}$ \\
\hline $\mathbf{8}$ & pedicel length $(\mathrm{cm})$ & $1.57^{\mathrm{b}}$ & $1.20^{\mathrm{b}}$ & $0.48^{\mathrm{a}}$ \\
\hline $\mathbf{9}$ & Petal length $(\mathrm{cm})$ & $4.62^{* *}$ & $4.44^{* *}$ & $3.28^{* *}$ \\
\hline $\mathbf{1 0}$ & Petal breadth $(\mathrm{cm})$ & $3.91^{* *}$ & $4.42^{* *}$ & $3.44^{* *}$ \\
\hline $\mathbf{1 1}$ & Pollen size diameter( $\mu)$ & $39.93^{* *}$ & $18.00^{* *}$ & $35.56^{* *}$ \\
\hline $\mathbf{1 2}$ & Pollen fertility $(\boldsymbol{\%})$ & $93.83^{* *}$ & $0.70^{* *}$ & $94.10^{* *}$ \\
\hline $\mathbf{1 3}$ & Length of pistil $(\mathrm{cm})$ & $2.20^{\mathrm{b}}$ & $2.66^{\mathrm{b}}$ & $1.74^{\mathrm{a}}$ \\
\hline $\mathbf{1 4}$ & Gossypol gland density & $6.50^{\mathrm{a}}$ & $8.25^{\mathrm{b}}$ & $9.75^{\mathrm{b}}$ \\
\hline
\end{tabular}

** Significant difference at $\mathrm{P}<0.01$ using Duncan's Multiple Range Test

The letters in the same alphabet are considered as non- significant 
Plate.1 Parents used for crossing

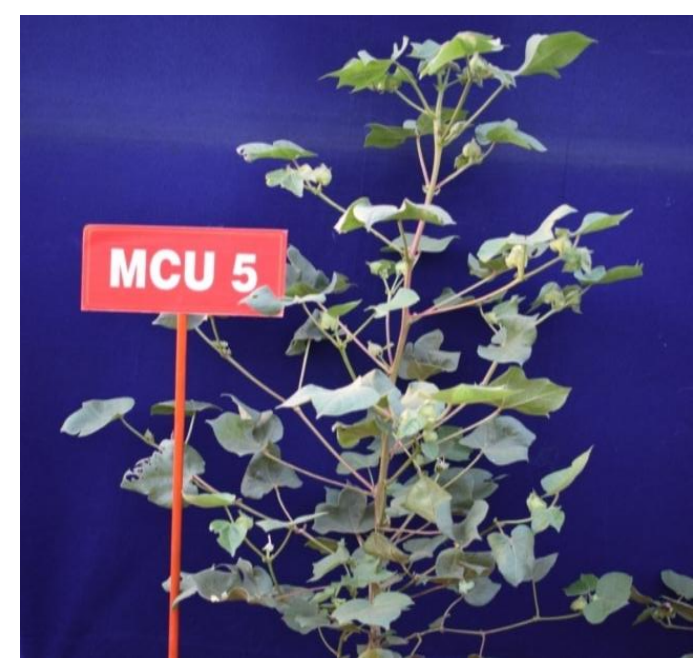

MCU 5

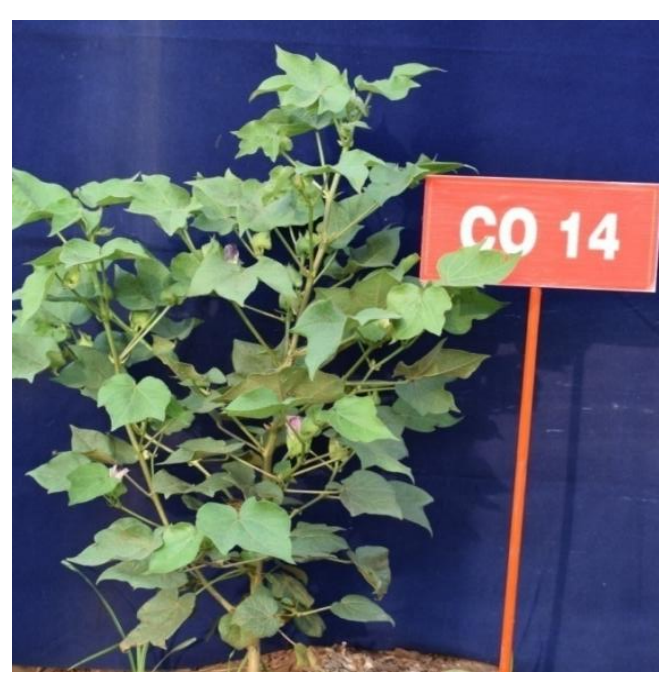

CO 14

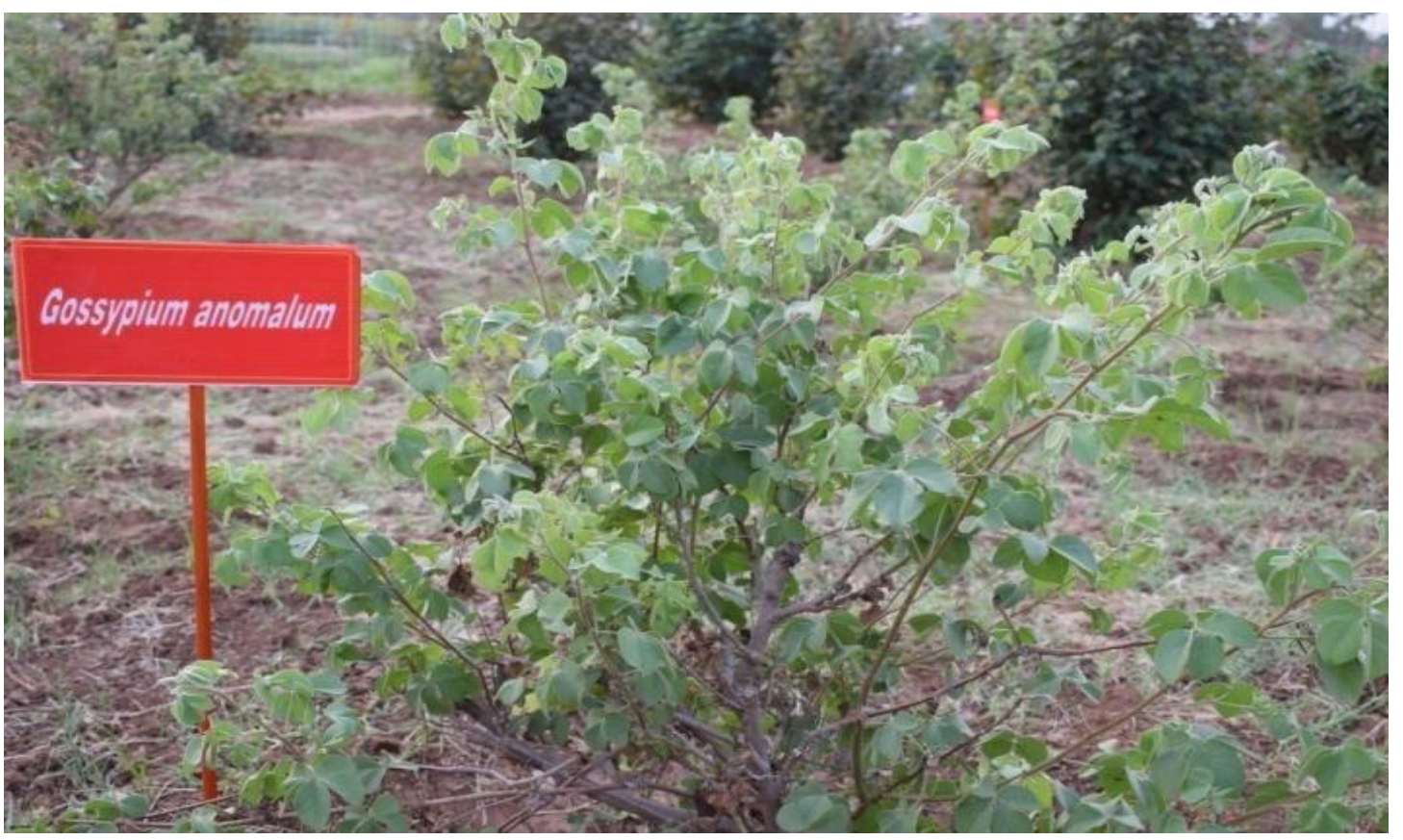

Gossypium anomalum 
Plate.2 Morphological features of parents and hybrids
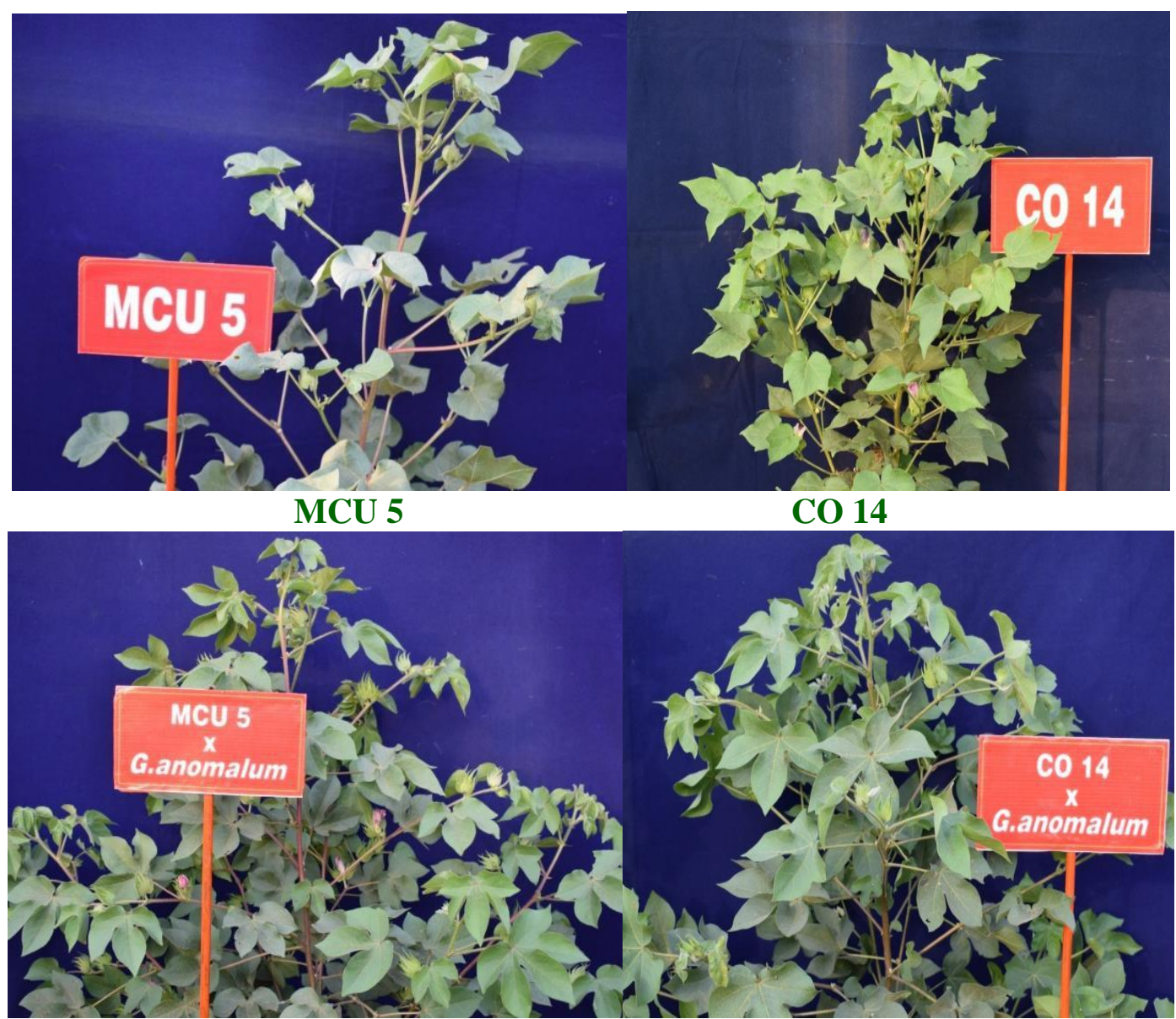

\section{MCU 5 x G. anomalum CO 14 x G. anomalum}

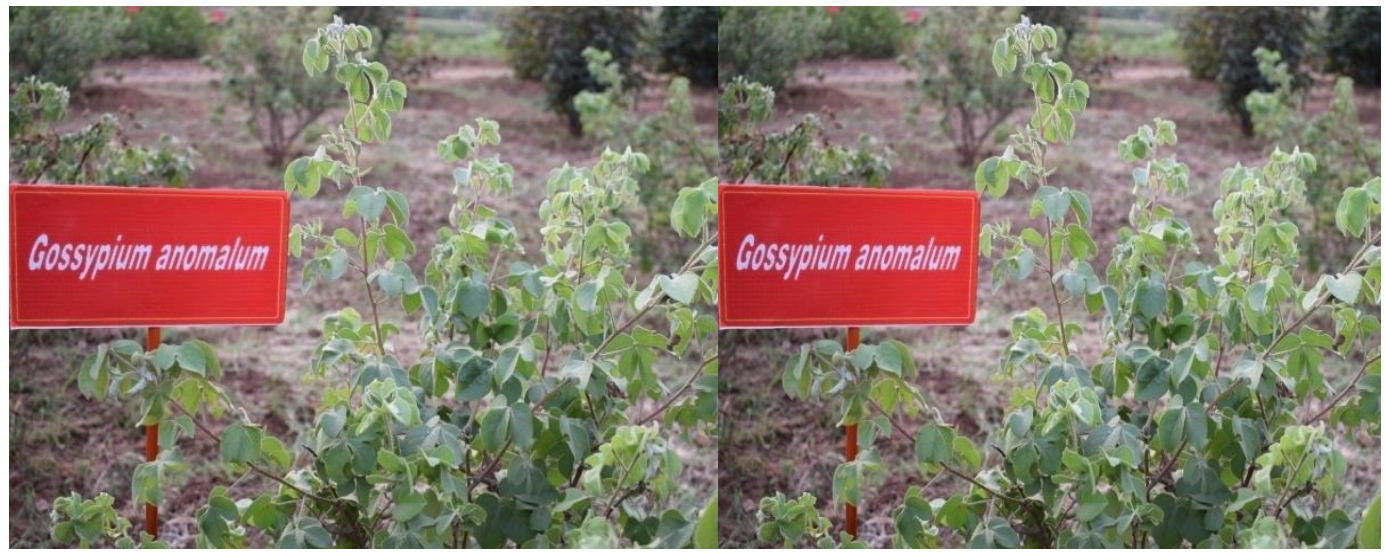

G.anomalum

G.anomalum 
Plate.3 Floral morphology of parents and hybrids
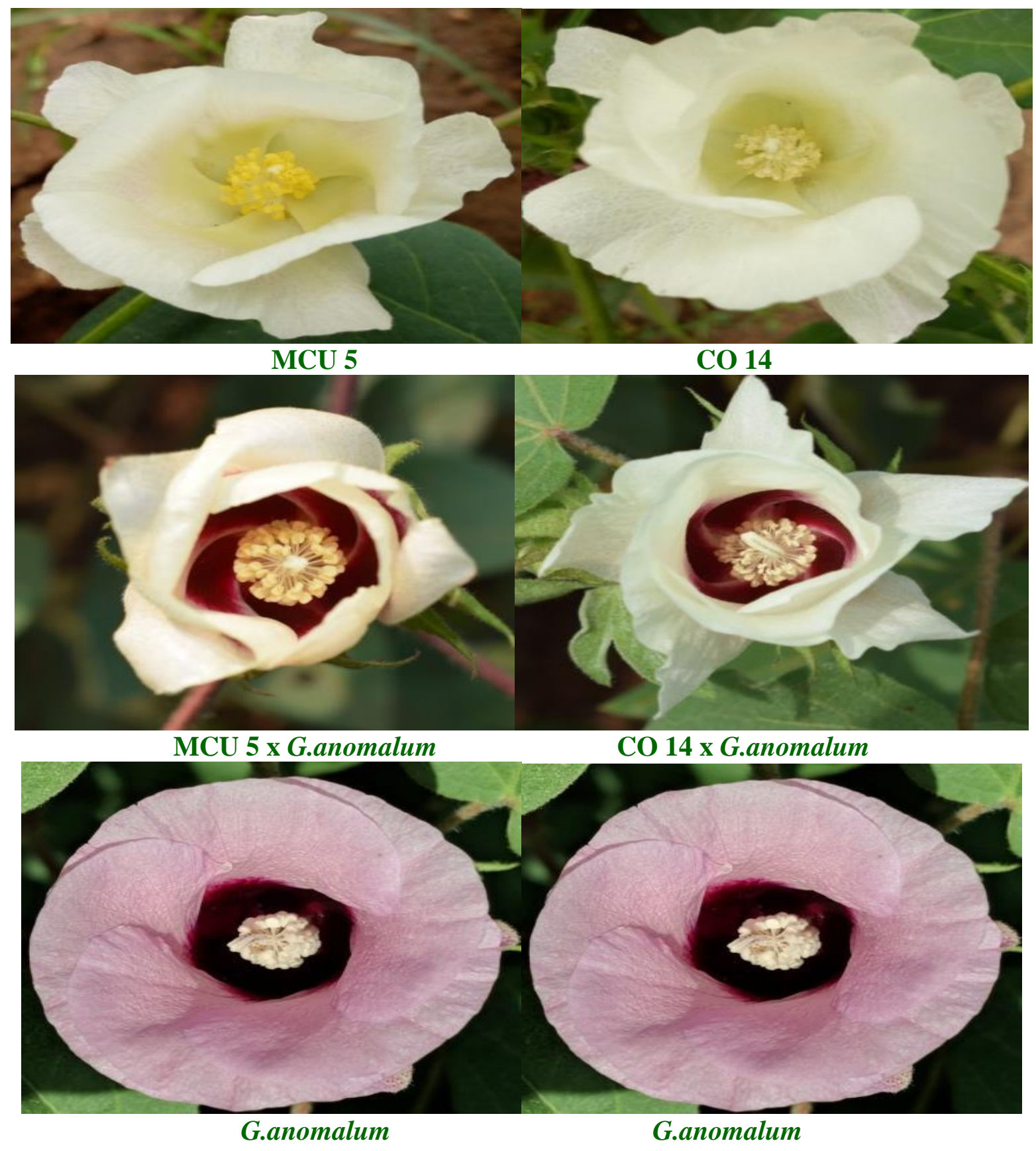
Plate.4 Petal morphology of parents and hybrids
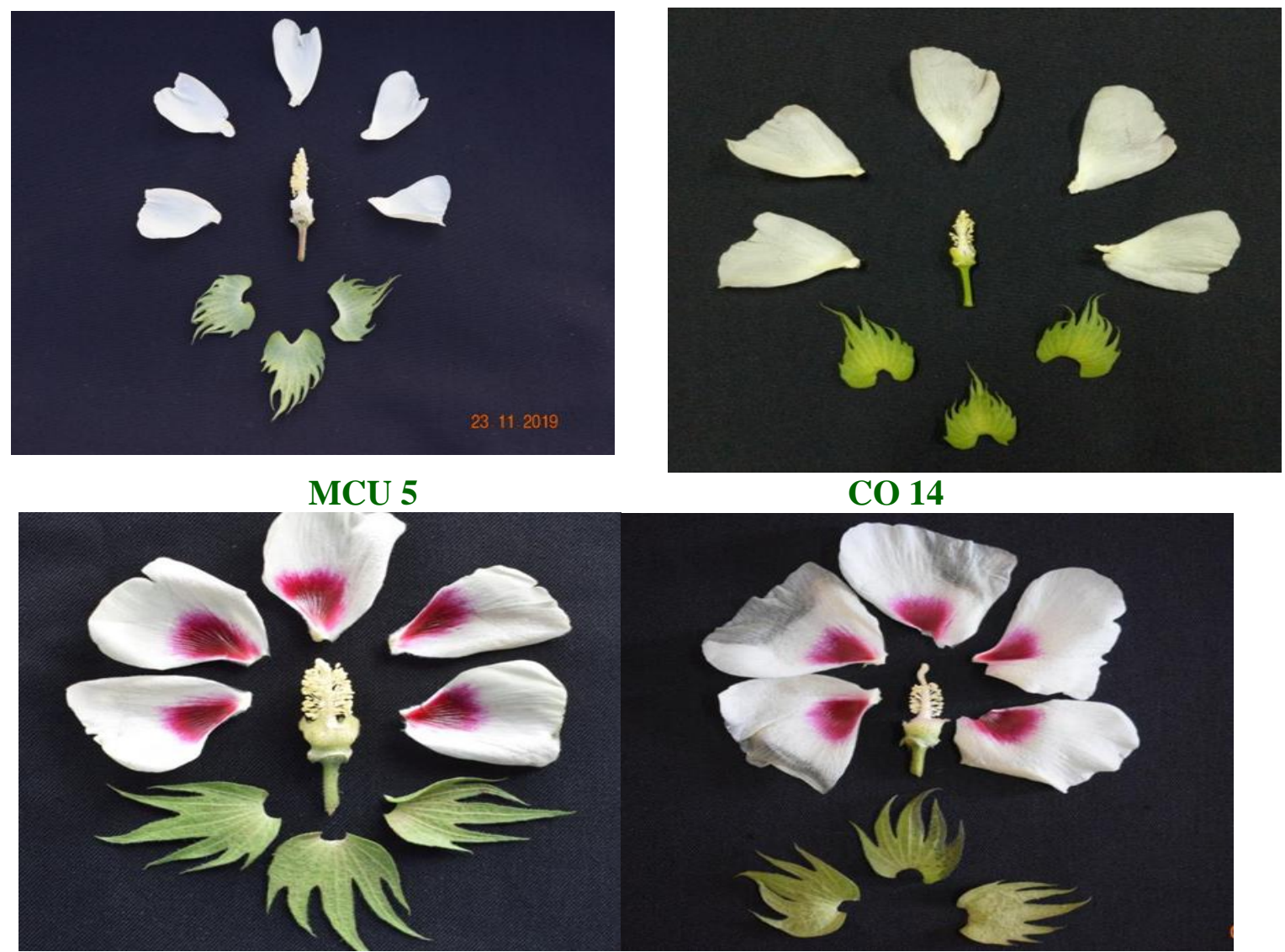

MCU 5 x G.anomalum
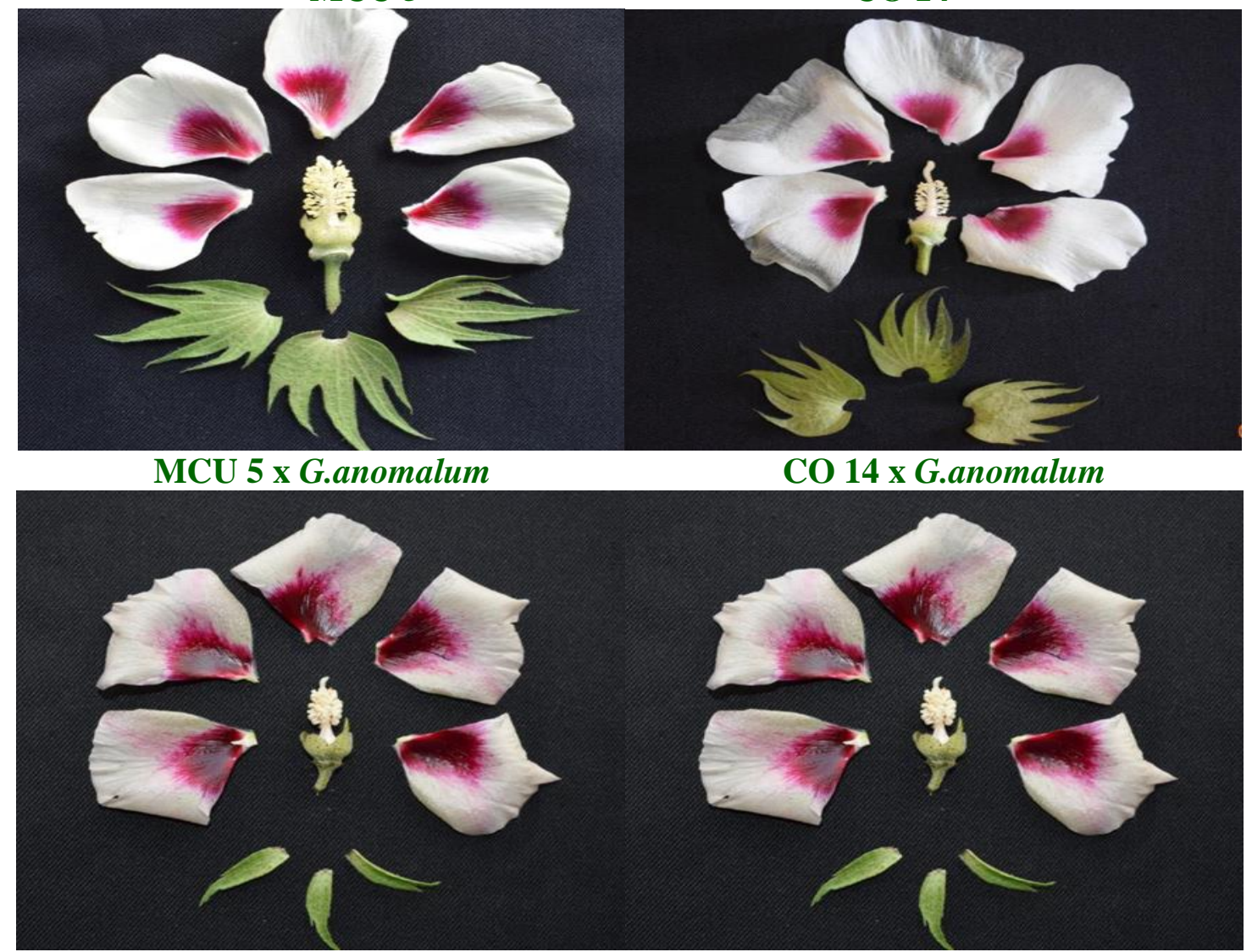

CO 14 x G.anomalum
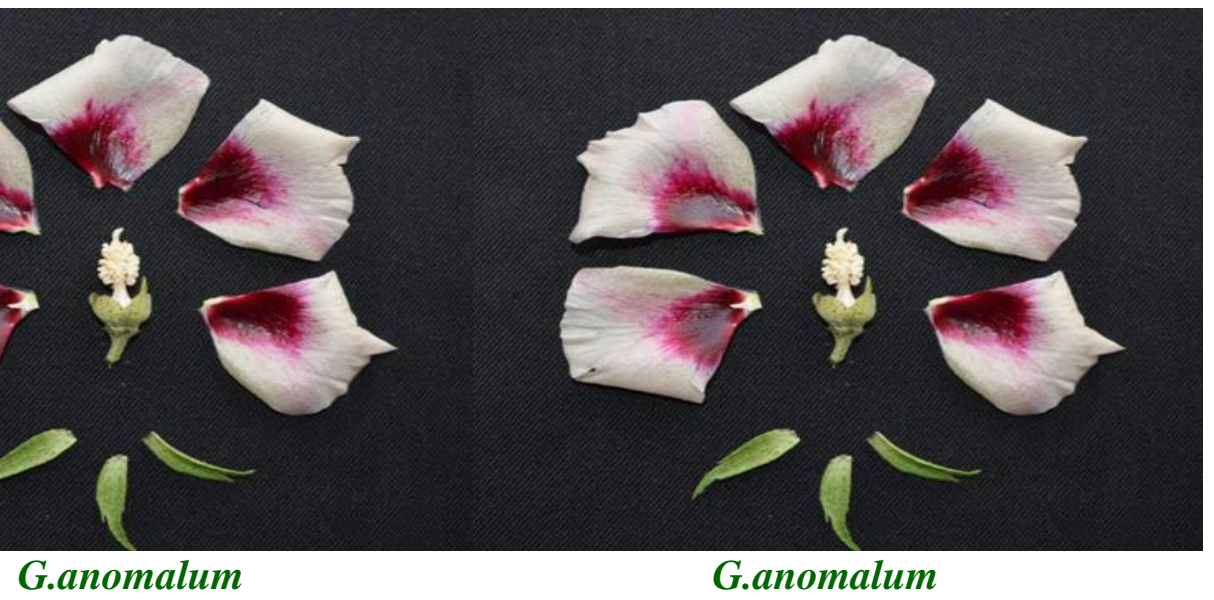

G.anomalum 
Plate.5 Pollen fertility of parents and hybrids
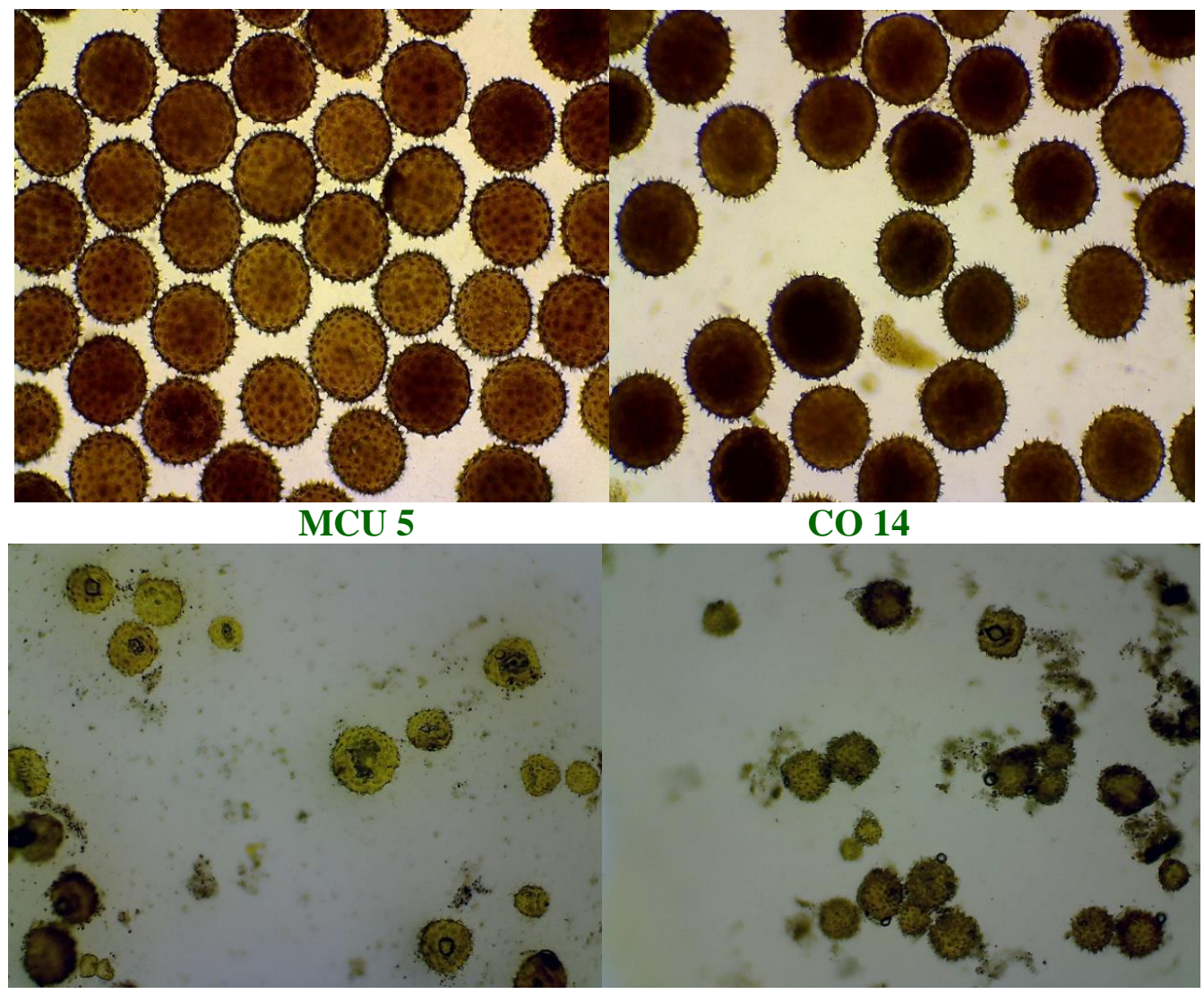

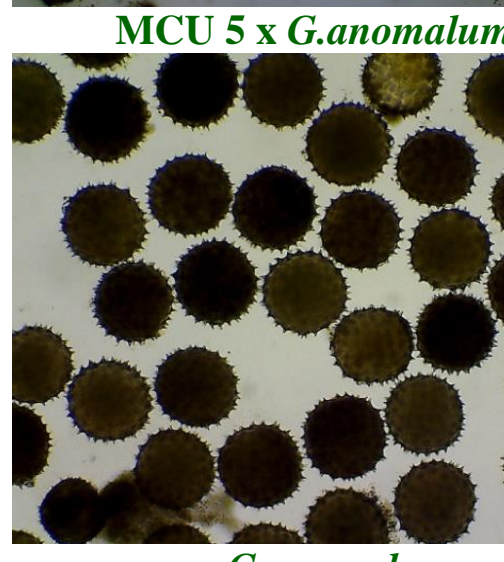

G.anomalum

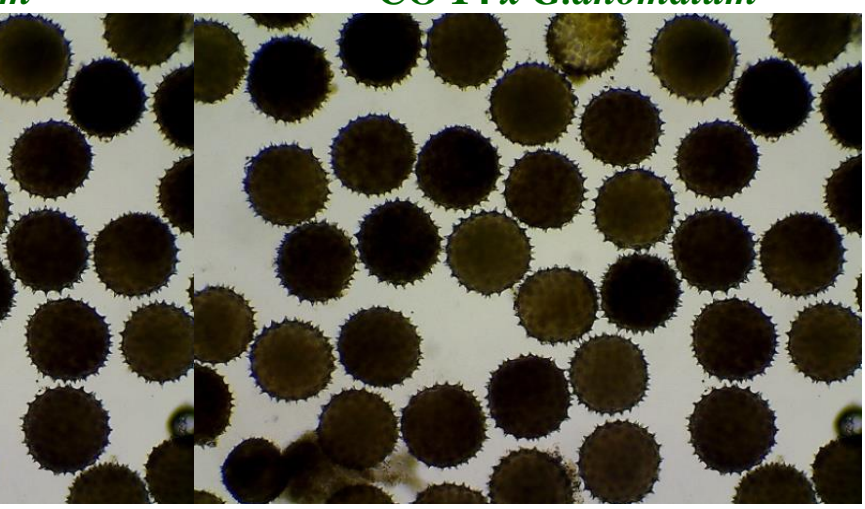

G.anomalum 
Plate.6 Mitotic chromosomal study in parents and hybrids

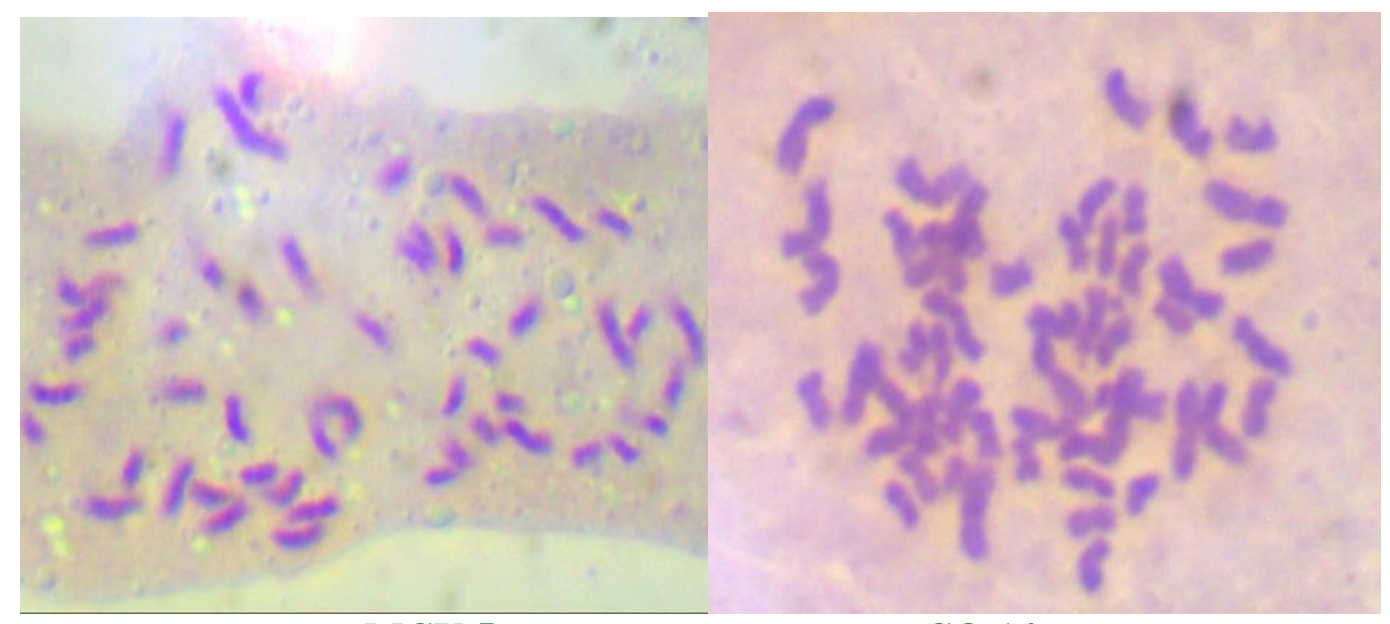
MCU 5
CO 14

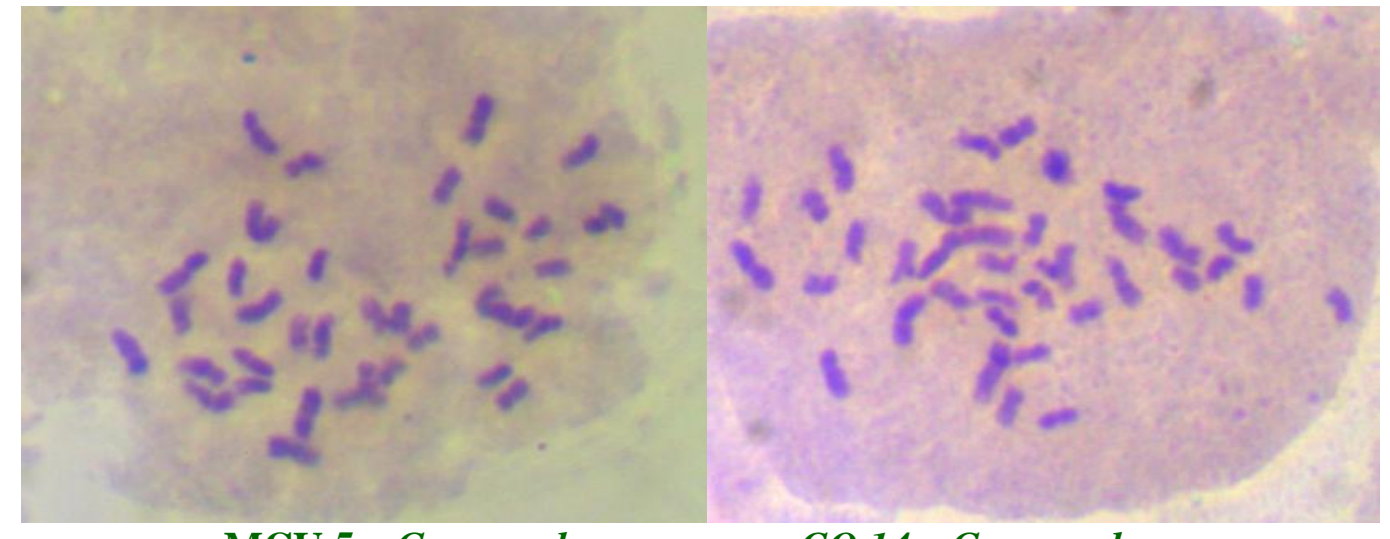

MCU 5 x G.anomalum

CO $14 x$ G.anomalum

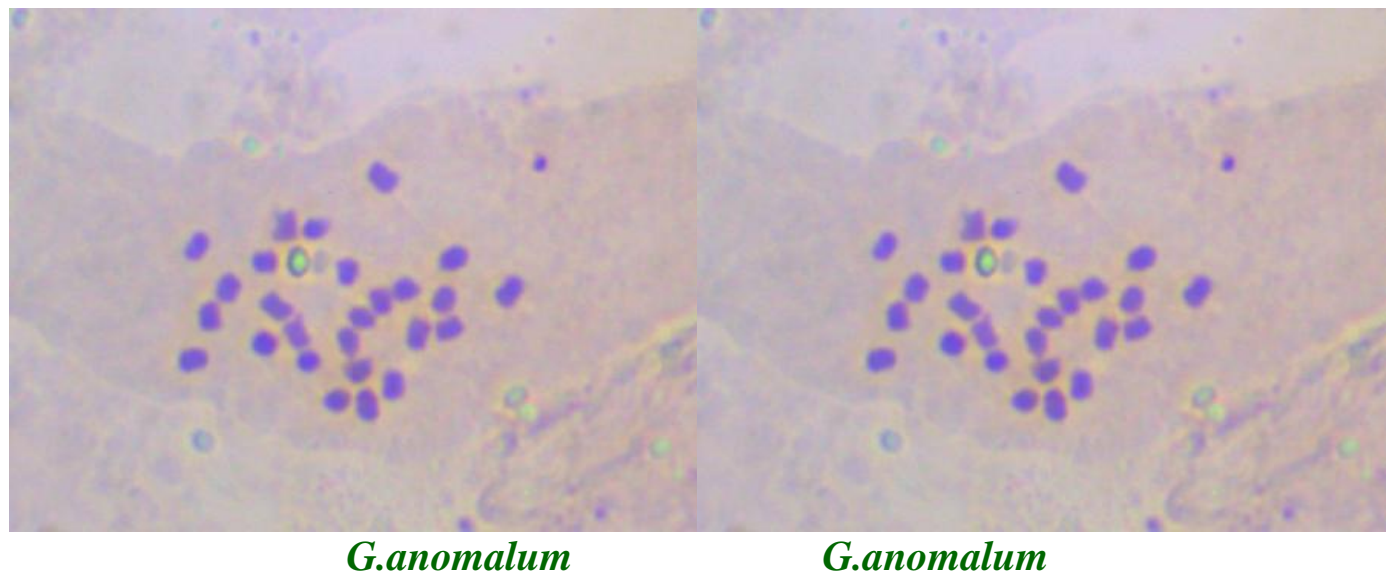

\section{References}

Ahmad, S., K. Mahmood and M. Hanif. 2011. Introgression of cotton leaf curl virusresistant genes from Asiatic cotton (Gossypium arboretum) into upland

\section{G.anomalum}

cotton (G. hirsutum). Genet. Mol. Res., 10(4): 2404-2414

Benbouza, H., J.M. Lacape, J.M. Jacquemin, B. Courtois, F.B.H. Diouf, D. Sarr, N. Konan, J.P. Baudoin and G. Mergeai. 2010. Introgression of the low-gossypol 
seed \&high-gossypol plant trait in upland cotton: analysis of [(Gossypium hirsutum $\times$ Graimondii) $2 \times$ G. sturtianum] trispecific hybrid and selected derivatives using mapped SSRs, Mol. Breed., 25: 273-286

Culp, T.W and D.C. Harrell. 1973. Breeding methods for improving yield and fiber quality of upland cotton (Gossypium hirsutum L.), Crop Sci., 13: 686-689

Culp, T.W., D.C. Harrell and T. Kerr. 1979. Some genetic implications in the transfer of high fiber strength genes to upland cotton, Crop Sci., 19; 481-484

Doak, C.C.1934. A new technique in cotton hybridization suggested changes in existing methods of emasculating and bagging cotton flowers. J. Hered., 25: 201-204

Fryxell, P.A. 1992. A revised taxonomic interpretation of Gossypium L. (Malvaceae), Rheedea 08-165.

Ganesh, S.N., P.C. Vivek, S.M. Subhash and S.J. Ashok. 2013. Interspecific hybridization in Gossypium L.: characterization of progenies with different ploidy-confirmed multigenomic backgrounds. Plant Breed., 132: 211-216

Heitholt, J. and R. Mauney. 2010. Physiology of Cotton, Springer, Netherland. Pp. 1-18.

Kale, M., S. Mehetre, G. Santosh, S. Gorakh and P. Vitthal. 2007. Cyto-morphological and RAPD analysis of $\mathrm{F}_{1}, \mathrm{~F} 2$ and $\mathrm{BC} 1$ generations of a cross Gossypium arboreum x Gossypium thurberi." Caryologia, 60(4): 379-388

Kaur, H., D. Pathak and P. Rathore. 2016. Development and characterization of an interspecific Gossypium hirsutumx Gossypium armourianum hybrid. Appl. Biol. Res., 18(2): 146-154.

Manickam, S and A.H. Prakash.2014. Interspecific hybridization between Gossypium hirsutum and Gossypium armourianum: Morphological and Molecular Characterization of Hybrids. Cotton Res. J., 6(1): 7-12.
Mehetre, S.S. 2010. Wild Gossypium anomalum: a unique source of fibre fineness and strength-overview and achievements of pre-breeding efforts. Curr. Sci., 99: 58-71.

Meyer, V.J. 1975. Male sterility from Gossypium harknessii. J. Hered., 66: 2327.

Percival, A.E. and J.M. Stewart. 1999. Taxonomy and Germplasm Resources, In: C.W. Smith, J. Cothren (eds) Cotton: Origin, History, Technology and Production. John Wiley \& Sons, Inc, NY, USA pp 33-63 J.F. Wendel, C.L. Brubaker, T. Seelanan, Chapter 1: The Origin and Evolution of Gossypium.

Pushpam, R and T. S. Raveendran. 2006. Production of interspecific hybrids between Gossypium hirsutem and Jassid resistant wild species $G$. raimondii and $G$. armourianum. Cytologia, 71(4): 407-418.

Liu,S.Y., J.Q. Huang, Y.J. Peng, B.L. Zhou, M.C. Ying, D.Z. Shen, G.L. Liu, T.X. Hu, Y.J. Xu, L.M. Gu, W.C. NI, S. Cheng. 1992. Studies on the hybrid of Gossypium hirsutum L. and $G$. anomalum and application in breeding, Sci. Agric. Sin., 25: 44-51.

Sacks, E.J. and A.F. Robinson.2009. Introgression of resistance to reniform nematode Rotylenchulus reniformis) into upland cotton (Gossypium hirsutum) from Gossypium arboretum and a $G$. hirsutum/Gossypium aridum bridging line. Field Crops Res., 112: 1-6.

Wendel, J.F. 1989. New World tetraploid cottons contain old world cytoplasm. Proc. Natl. Acad. Sci., U.S.A. 86: 41324136.

Wu, Yuxiang, Di Chen, Shuijin Zhu, Lufei Zhang and Lingjiao. 2017. "A New Synthetic Hybrid (A1D5) between Gossypium herbaceum and Gossypium raimondii and its morphological, cytogenetic, Molecular Characterization. PloS one, 12 (2): 1-11. 


\section{How to cite this article:}

Mahalingam, L., N. Premalatha, K. Senguttuvan, B. Rakavi and Kumar, M. 2020. Introgression of Traits from Wild Diploids into Cultivated Tetraploids: A Pragmatic Analysis Using Genetic and Cytogenetic Tool. Int.J.Curr.Microbiol.App.Sci. 9(07): 1486-1489.

doi: https://doi.org/10.20546/ijcmas.2020.907.170 